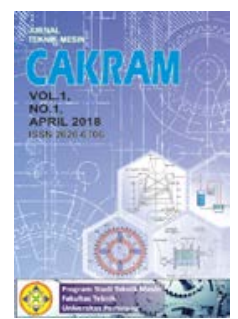

\title{
ANALISIS SIFAT MEKANIK, SIFAT FISIS DAN MAGNET KOMPOSIT MAGNET PERMANEN NdFeB DENGAN PEREKAT POLYVYNIL ALCOHOL (PVA)
}

\author{
Mulyadi \\ Program Studi Teknik Mesin, Universitas Pamulang, Jl. Surya Kencana No.1, Tangerang Selatan, Indonesia \\ E-mail : dosen01545@unpam.ac.id
}

Masuk : 5 Maret 2019

Direvisi : 28 Maret 2019

Disetujui : 8 April 2019

\begin{abstract}
Abstrak: Pada penelitian ini dilakukan pembuatan komposit magnet permanen Nd2Fe14B dengan menggunakan perekat Poly vynil alcohol (PVA), dengan tujuan untuk mengetahui pengaruh variasi penambahan PVA terhadap sifat mekanik, sifat fisis dan magnet komposist magnet Nd2Fe14B. Bahan baku yang digunakan serbuk magnet Nd2Fe14B Type MQP-B dan perekatnya cairan PVA. Variasi komposi PVA adalah 2, 3, 5 , 7 dan 9 \% berat. Kedua bahan baku dicampur sampai homogen, kemudian dicetak tekan dengan gaya 10 tonf membentuk pellet berdiameter $18 \mathrm{~mm}$ dan ketebalan $15 \mathrm{~mm}$. Kemudian pellet yang diperoleh dikeringkan didalam lemari pengering pada suhu 100oC selama 2 jam. Pelet yang telah kering di magnetisasi sehingga manjadi magnet. Selanjutnya dilakukan karakterisasi meliputi pengujian kuat tekan dan kekerasan (shore hardness D ),serta diukur densitas dan kekeuatan medan magnet. Hasil diperoleh menunjukkan bahwa semakin banyak komposisi PVA maka kuat tekan dan kekerasan cenderung meningkat dan sebaliknya densitas dan sifat magnetnya cenderung menurun. Komposisi yang terbaik pada sampel dengan $2 \%$ PVA dan diperoleh kuat medan magnet 1300 gauss.
\end{abstract}

Kata kunci : komposit magnet, Nd2Fe14B, PVA, kuat tekan, kekerasan, kuat medan magnet

\begin{abstract}
In this study, Nd2Fe14B permanent magnet composite was made using Poly vynil alcohol (PVA) adhesive, with the aim to determine the effect of variations in the addition of PVA to the mechanical properties, physical properties and magnetism of magnetic composers Nd2Fe14B. The raw material used is magnetic powder Nd2Fe14B Type MQP-B and the adhesive is PVA liquid. PVA composition variations are 2, 3, 5, 7 and $9 \%$ by weight. The two raw materials were mixed until homogeneous, then formed by force of 10 tonf to form a pellet with a diameter of $18 \mathrm{~mm}$ and a thickness of $15 \mathrm{~mm}$. Then the obtained pellet was dried in a drying chamber at $100 \mathrm{oC}$ for 2 hours. The dried pellets are magnetized so that they become magnets. Then characterization includes testing of compressive strength and hardness, and measuring the density and strength of the magnetic field. The results obtained showed that the more PVA composition, the compressive strength and hardness tend to increase and conversely the density and magnetic properties tend to decrease. The best composition in samples with $2 \%$ PVA and obtained magnetic field strength of 1300 gauss.
\end{abstract}

Keywords : composite magnet permanent, Nd2Fe14B, PVA, compressive strength, hardness, magnetic field strength

\section{PENDAHULUAN}

Material magnet berdasarkan fungsinya dibedakan menjadi dua jenis yaitu magnet lunak (soft magnetic) dan magnet permanen (hard magnet) [1]. Magnet lunak adalah material magnet yang memiliki nilai koersivitas yang rendah yaitu kurang dari 100 Oe [1]. Aplikasi material magnet ini untuk keperluan penyerap gelombang mikro pada anti radar (adsorber), komponen elektronik (sensor dan switching) dan untuk aplikasi yang lebih maju diguanakan sebagai media drug delivery (nano soft magnetic). Bahan pembentuk magnet lunak adalah Zn-Ferrite, Ni-Ferrite, Mn-Zn -Ferrite dan nano Fe3O4 [2]. Magnet permanen adalah jenis magnet keras (hard magnet) yang memiliki 
sifat magnet yang permanen dan sulit untuk dihilangkan. Nilai koersivitas magnet permanen umumnya cukup besar yaitu > 500 Oe, dimana nilai koersivitas yang paling tinggi bisa mencapai 6 - 8 kOe [2,3]. Material magnet permanen terdiri dari beberapa golongan yaitu : berbasis logam paduan (AlNiCo, CoSm), berbasis oksida besi ( Baferrit BaO6Fe2O3, SrO6 Fe2O3) dan berbasis logam tanah jarang (Nd2Fe14B) [4]. Tentunya ketiga jenis magnet permanen tersebut memiliki sifat-sifat magnet yang berbeda, dimana magnet permanen jenis logam tanah jarang (Nd2Fe14B) memiliki sifat magnet paling tinggi dibandingkan dengan jenis magnet permanen lainnya [3,4]. Pada Tabel 1 diperlihatkan sifat-sifat magnet yaitu temperature curie (Tc), remanensi (Br), energi produk (BHmax dan koersivitas (Hc) dari beberapa jenis magnet permanen.

Tabel 1. Perbandingan sifat -sifat magnet beberapa jenis magnet permanen [4]

\begin{tabular}{ccccc}
\hline Bahan & $\mathbf{T c} \mathbf{~}^{\mathbf{0}} \mathbf{C}$ & $\mathbf{( B H )} \mathbf{~ m a x}, \mathbf{k J} / \mathbf{m}^{\mathbf{3}}$ & $\mathbf{B r}, \mathbf{T e s l a}$ & Hc (kOe) \\
\hline $\mathrm{SrO} .6 \mathrm{Fe}_{2} \mathrm{O}_{3}$ (isotropi) & 450 & 28 & 0,39 & 2,65 \\
$\mathrm{BaO} .6 \mathrm{Fe}_{2} \mathrm{O}_{3}$ (isotropi) & 450 & 6,0 & 0,2 & 1,16 \\
$\mathrm{AlNiCo}_{4}$ & 850 & 72 & 1,04 & 1,24 \\
$\mathrm{SmCo}_{5}$ & 720 & $130-180$ & $0,8-1,15$ & $6,00-6,70$ \\
$\mathrm{Nd}_{2} \mathrm{Fe}_{14} \mathrm{~B}$ & 310 & $200-350$ & $1,0-1,3$ & $6,00-8,50$ \\
\hline
\end{tabular}

Aplikasi dari magnet permanen cukup luas yaitu : sebagai media filter logam ferrous, komponen kopling pada meteran air, komponen generator listrik, komponen motor listrik DC, dan lain-lain [4]. Magnet permanen berdasarkan proses pembuatannya dibedakan dalam dua kelompok yaitu magnet sinter dan komposit magnet. Magnet sinter adalah jenis magnet yang dibuat melalui tahapan proses pembakaran pada suhu tinggi mendekati titik leburnya atau disebut proses sintering [5]. Sedangkan komposit magnet adalah jenis magnet permanen yang dibuat dari campuran serbuk magnet dengan bahan perekat tanpa melalui proses sintering, disisni bahan perekat berfungsi menyatukan pertikel-partikel magnet [5]. Beberapa bahan perekat yang dapat digunakan untuk pembuatan komposit magnet adalah : epoxy resin, nylon pasta, poly vynil butiral (PVB) dan Poly Vynil Alcohol (PVA) [6]. Beberapa penulis telah melakukan penelitian pembuatan komposit magnet menggunakan perekat epoxy resin, nylon, melalui proses ekstrusi dan kompaksi [6]. Penelitian yang dilakukan menggunakan perekat PVA dan melalui teknik kompaksi. Beberapa parameter proses dalam pembuatan komposit magnet yang dapat mempengaruhi sifat-sifat komposit magnet antara lain : ukuran kehalusan serbuk magnet, komposisi bahan perekat dan tingkat kepadatan komposit. Beberapa author telah melakukan pembuatan komposit magnet Nd2Fe14B dengan perekat epoxy resin, persentase penambahan resin memberikan pengaruh terhadap sifat mekanik dan sifat magnet yatu semakin besar komposisi epoxy resin maka kekuatan mekanikmeningkat dan sifat magnet cenderung menurun [7]. Kekuatan magnet tertinggi dicapai pada sampel denga 5 \% bear epoxy resim yaitu diperoleh kekuatan medan magnet 1100 Gauss [7]. Penelitian ini dilakukan untuk membuat komposit magnet berbasis Nd2Fe14B melalui porses kompaksi. Tujuan dari penelitian ini adalah untuk mengetahui pengaruh komposisi perekat PVA terhadap kekuatan mekanik (kuat tekan dan kekerasan), sifat fisis (densitas) dan sifat magnet (kekuatan medan magnet).

\section{METODOLOGI}

Pada penelitian ini dilakukan pembuatan komposit magnet permanen Nd2Fe14B dengan bahan baku meliputi serbuk magnet Nd2Fe14B type MQP-B dan perekatnya cairan PVA. Komposi PVA divariasikan yaitu meliputi : 2, 3, 5 , 7 dan 9 \% berat. Selanjutnya kedua bahan baku dicampur sampai homogen, kemudian dicetak tekan menggunakan hidraulik press dengan gaya 10 tonf membentuk pellet berdiameter 18 mm dan ketebalan 15 mm. Kemudian pellet yang diperoleh dikeringkan didalam lemari pengering pada suhu 100oC selama 2 jam. Pelet yang telah kering di magnetisasi menggunakan impulse magnetizer sehingga manjadi magnet. Selanjutnya dilakukan karakterisasi meliputi pengujian kuat tekan dan kekerasan (shore hardness D ),serta diukur densitas dan kekeuatan medan magnet. Perhitungan nilai kuat tekan dilakukan dengan menggunakan persamaan :

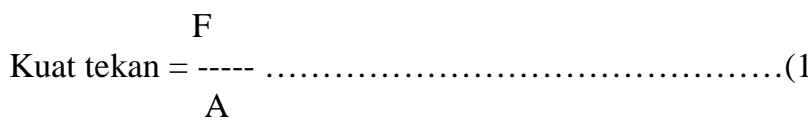

dimana : 


$$
\begin{array}{ll}
\mathrm{F} & =\text { gaya tekan }(\mathrm{kgf}) \\
\mathrm{A} & =\text { luas penampang sampel }\left(\mathrm{cm}^{2}\right)
\end{array}
$$

Pengukuran kekerasan digunakan kekerasan (shore hardness D ) komposit dilakukan dengan menggunakan beban sebesar 800 gf dengan alat Durometer. Untuk pengukuran densitas digunakan metoda Archimedes, dan menggunakan media aquades. Nilai densitas dihitung dengan menggunakan persamaan :

$$
\rho=\frac{M k}{\text { Mb- Mg-Mkwt }}
$$

dimana :

$$
\begin{array}{ll}
\rho & =\text { densitas sampel }\left(\mathrm{g} / \mathrm{cm}^{3}\right) \\
\mathrm{Mk} & =\text { massa kering sampel }\left(\mathrm{g} / \mathrm{cm}^{3}\right) \\
\mathrm{Mb} & =\text { massa benda digantung didalam air }\left(\mathrm{g} / \mathrm{cm}^{3}\right) \\
\mathrm{Mkwt} & =\text { massa kawat penggantung }\left(\mathrm{g} / \mathrm{cm}^{3}\right)
\end{array}
$$

Pengukuran kuat medan magnet pellet dilakukan dengan menggunakan alat Gaussmeter.

\section{HASIL DAN PEMBAHASAN}

Hasil pengukuran densitas sebagi fungsi dari persentase bahan perekat PVA dipelihatkan pada Gambar 1.

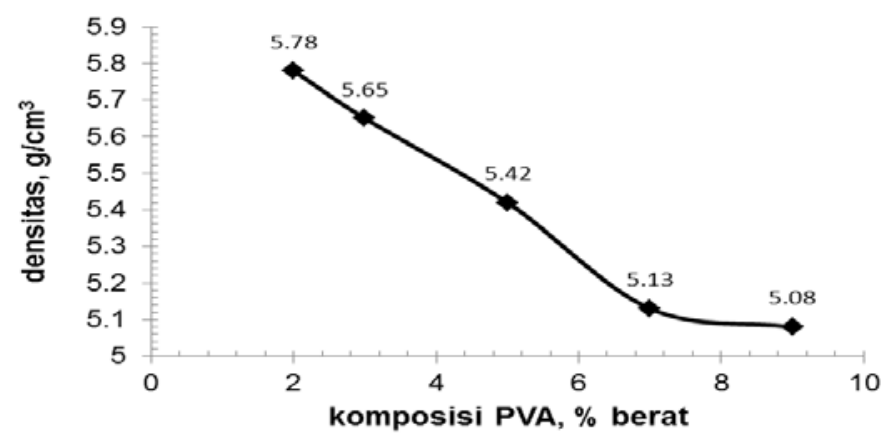

Gambar 1. Kurva densitas terhadap komposisi perekat PVA.

Berdasarkan hasil pada Gambar 1 menujukkan bahwa semakin banyak komposisi perekat PVA nilai densitasnya cenderung menurun, hal ini disebabkan densitas bahan perekat polimer PVA $\left(1,25 \mathrm{~g} / \mathrm{cm}^{3}\right)$ lebih rendah dibandingkan dengan densitas partikel NdFeB $\left(6-7 \mathrm{~g} / \mathrm{cm}^{3}\right)$. Densitas tertinggi dicapai pada komposisi PVA 2 \% dan $3 \%$ yaitu nilai densitas masing masing adalah $5,78 \mathrm{~g} / \mathrm{cm}^{3}$ dan 5,65 g/ $\mathrm{cm}^{3}$.

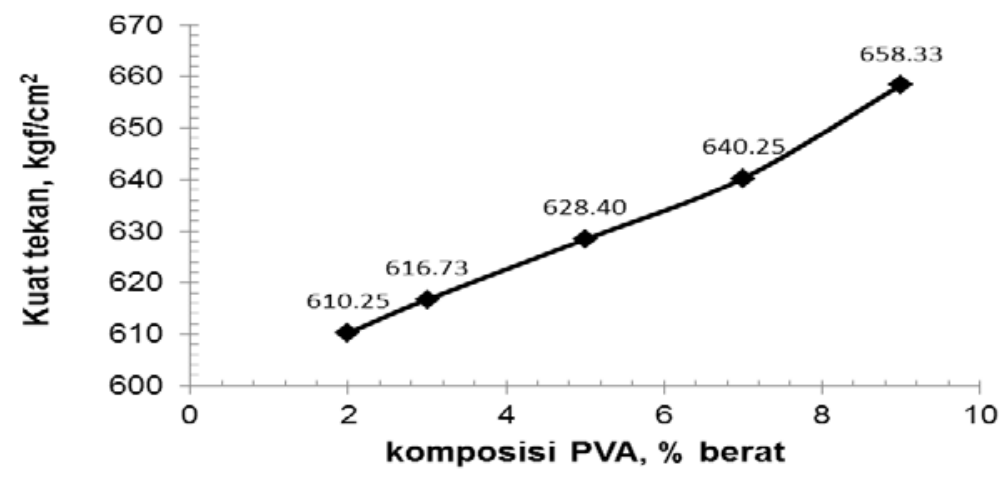

Gambar 2. Kurva hubungan kuat tekan denganpersentase komposisi PVA. 
Hasil penukuran kuat tekan diperlihatkan pada Gambar 2, dimana semakin banyak bahan perekat maka partikel-partikel NdFeB semakin kuat terikat sehingga semakin banyak perekat PVA maka nilai kuat tekan semakin besar.Nilai tertinggi kuat tekan yaitu masing-masing 640,25 kgf/cm ${ }^{2}$ dan 658,33 kgf $/ \mathrm{cm}^{2}$ dengan perekat masing masing $7 \%$ dan $9 \%$.

Hasil pengukuran kekerasan dilakukan menggunakan Durometer shore D, hasil pengukuran diperlihatkan pada Gambar 3.

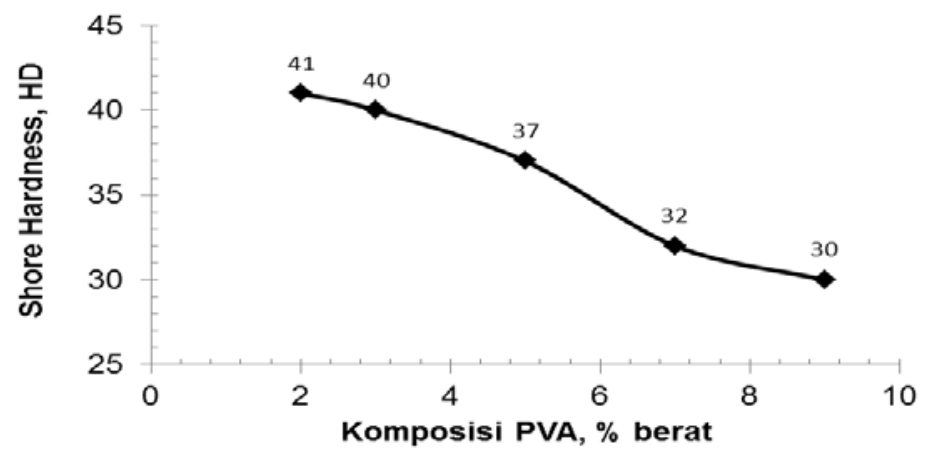

Gambar 3. Kurva hubungan kekerasan terhadap komposisi perekat PVA.

Berdasarkan kurva kekerasan pada Gambar 3 menunjukkan bahwa semakin banyak perekat PVA maka nilai kekerasan cenderung menurun dan sampel kmposit cenderung lebih lunak. Hal ini disebabkan bahwa semakin besar komposisi PVA maka jumlah partikel magnetik NdFeB cenderung berkurang dan kekerasan partikel NdFeB lebih besar dibandingkan bahan polimer PVA. Nilai tertinggi kekerasan dicapai sebesar 41 HD dan 40 HD pada komposisi PVA masing-masing $2 \%$ dan $3 \%$.

Pengukuran kuat medan magnet dilakukan menggunakan Gaussmeter dan hasil pengukuran diperlihatkan pada Gambar 4.

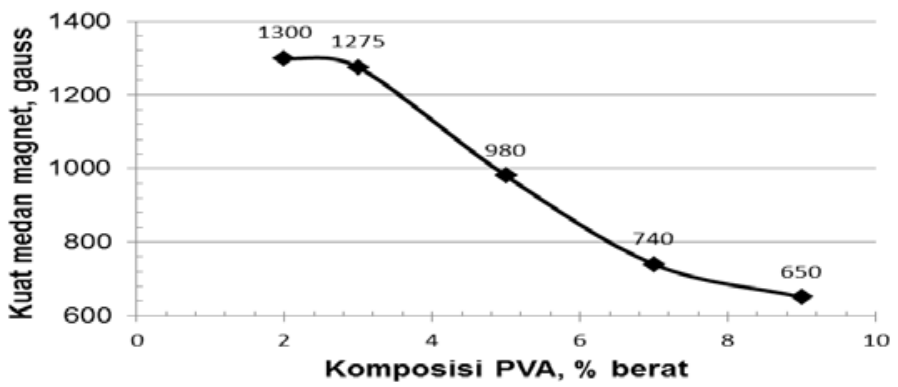

Gambar 4. Kurva kuat medan magnet terhadap komposisi PVA.

Pada Gambar 4 menunjukkan bahwa semakin besar komposisi PVA nilai kuat medan magnet cenderung menurun, hal ini dikarenakan bahwa semakin banyak bahan perekat PVA maka partikel magnetik akan berkurang, disamping itu perekat PVA bersifat non magnetik. Jadi jika jumlah non magnetik bertambah maka sifat magnet (kuat medan magnet) dari komposit juga cenderung menurun. Nilai kuat medan magnet terbesar dicapai pada sampel komposit dengan perekat 2 \% dan 3 \% yaitu nilainya masing-masing sebesar 1300 gauss dan 1275 Gauss.

Berdasarkan hasil pembuatan komposit magnet permanen NdFeB dengan menggunakan perekat polimer PVA serta karakterisasi sifat fisis, mekanik dan magnet mnunjukkan bahwa sesuai dengan fungsi komposit magnet dalam bidang magnet maka komp,osisi terbaik diambil berdasarkan sifat magnetnya. Maka berdasarkan hasil pengujian bahwa sampel yang memiliki kuat medan magnet tertinggi terdapat pada sampel dengan perekat PVA 2 \% dan $3 \%$, tetapi kalau diambil berdasarkan kekuatan mekanik yaitu kuat tekan tertinggi diperoleh pada sampel dengan perekat PVA 7 \% dan $9 \%$. 


\section{KESIMPULAN}

Dari hasil penelitian pembuatan dan karakterisasi komposit magnet permanen berperekat polimer PVA dapat disimpulkan :

a. Komposisi perekat polimer PVA memberikan pengaruh yang siqnifikan terhadap sifat fisis, mekanik dan sifat magnet.

b. Nilai tertinggi densitas $(4,78 \mathrm{~g} / \mathrm{cm} 3)$,kekerasan (41 HD) dan kuat medan magnet (1300 Gauss) dicapai pada sampel komposit dengan perekat $2 \%$ PVA.

c. Sedang kuat tekan tertinggi $(658 \mathrm{kgf} / \mathrm{cm} 2)$ terdapat pada sampel dengan perekat $9 \%$ PVA.

\section{DAFTAR PUSTAKA}

[1]. K.H.J. Buschow, Handbook of Magnetic Materials, vol 18, First Edition, pp. 15-28, 200

[2]. COEY J. M. D, Magnetism and Magnetic Materials, Published in the United States of America by Cambridge University Press, New York,2010.

[3].Suprapedi, Muljadi, Priyo Sardjona and Ramlan, Effect of silicon rubber composition on mechanical, magnetic properties and micro structures on Neodymium Iron Boron composite, Journal of Physics: Conf. Series 1120, 012037, doi:10.1088/1742-6596/1120/1/012037, 2018.

[4]. Peter C. Dent, Rare earth elements and permanent magnets (invited), Journal of Applied Physics 111, 07A721, 2015.

[5]. Perdinan Sinuhaji, Muljadi, Prijo Sardjono, Elprida Lingga, Averroes F Piliang, The Effect of Composite Bonded Magnet NdFeB/BaFe12O19 Composition with an Addition of Bakelite to Physical and Magnetic Properties, Journal of Physics: Conf. Series 1120,012026 , doi:10.1088/1742-6596/1120/1/012026, 2018.

[6]. Monika G. Garrell, Albert J. Shih, Bao-Min Ma, Edgar Lara-Curzio, Ronald O. Scattergood, Mechanical properties of Nylon bonded $\mathrm{Nd}-\mathrm{Fe}-\mathrm{B}$ permanent magnets, Journal of Magnetism and Magnetic Materials 257, 32-43, 2003.

[7]. M. Drak., and L.A. Dobrzański, Hard Magnetic Materials Nd-Fe-B/Fe with Epoxy Resin Matrix, Journal of Achievements in Materials and Manufacturing Engineering Vol. 24, Issue 2 , 2007. 